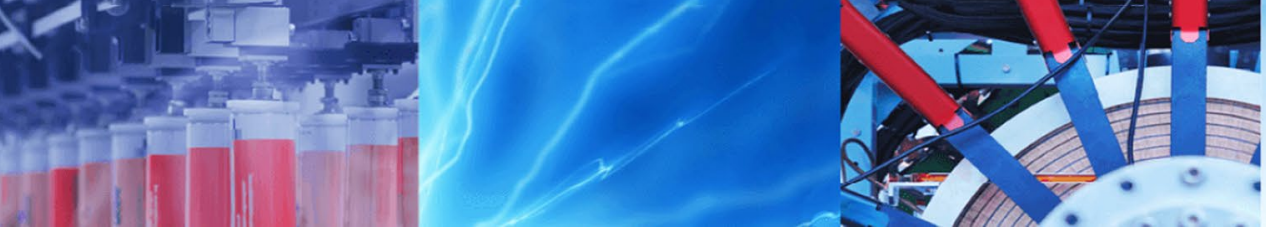

Research Article

\title{
Supercapacitors based on free-standing reduced graphene oxides/ carbon nanotubes hybrid films
}

\author{
Zhi-Guang Yang ${ }^{1} \cdot$ Ning-Ning Liu ${ }^{1} \cdot$ Shuo Dong ${ }^{1} \cdot$ Feng-Shou Tian ${ }^{1} \cdot$ Yong-Ping Gao ${ }^{2} \cdot$ Zhi-Qiang Hou $^{1}$ (I)
}

(c) Springer Nature Switzerland AG 2018

\begin{abstract}
The freestanding of reduced graphene oxides/carbon nanotubes (rGO/CNTs) hybrid films are synthesized via the simple vacuum filtration and thermal reduction methods. And the electrochemical behaviors of $\mathrm{rGO} / \mathrm{CNTs}$ hybrid films are investigated in $\mathrm{KOH}$ and in $\mathrm{Et}_{4} \mathrm{NBF}_{4} / \mathrm{AN}$ electrolyte, respectively. In three-electrode systems, the $\mathrm{rGO} / \mathrm{CNTs}$ hybrid films show a maximum specific capacitance of $221 \mathrm{~F} \mathrm{~g}^{-1}$, a $71 \%$ capacitance retention, and an excellent cycle life in $1 \mathrm{M} \mathrm{KOH}$ electrolyte. And the electrochemical behaviors of $\mathrm{rGO} / \mathrm{CNTs}$ films in $\mathrm{Et}_{4} \mathrm{NBF}_{4} / \mathrm{AN}$ electrolyte under three-electrode systems show a maximum specific capacitance of $174 \mathrm{~F} \mathrm{~g}^{-1}$ and good rate capability. Moreover, a symmetric supercapacitor of $\mathrm{rGO} /$ $\mathrm{CNTs} / / \mathrm{rGO} / \mathrm{CNTs}$ demonstrates a maximum specific capacitance of $24 \mathrm{~F} \mathrm{~g}^{-1}$ at $1 \mathrm{~A} \mathrm{~g}^{-1}$, a energy density of $20.8 \mathrm{Wh} \mathrm{kg}^{-1}$ at $1.27 \mathrm{~kW} \mathrm{~kg}^{-1}$, and an excellent cycle life of $86.1 \%$ retention after 5000 cycles. It suggests that the symmetric supercapacitor could be regarded as an ideal energy storage system.
\end{abstract}

Keywords Supercapacitor · Reduced graphene oxides · Free-standing electrodes $\cdot \mathrm{Et}_{4} \mathrm{NBF}_{4} / \mathrm{AN}$ electrolyte

\section{Introduction}

Among the various energy storage devices, supercapacitors are drawn the great attention due to its high power density, rapid charge and discharge, and good cycle stability [1-8]. And it has been successfully applied in electronic products, flexible and wearable electronic devices, and hybrid electric vehicles $[9,10]$. However, the low energy density of supercapacitors still couldn't satisfy the people's demands [11]. To resolve these obstacles, the researcher have devoted to much time and energy to develop the novel supercapacitors. In recent years, they have realized that the good electrode materials and the rational structure of supercapacitor are the key to obtain the high electrochemical performance supercapacitors $[12,13]$.

As reported, the electrode materials mainly focus on carbon materials, transition metal oxides/hydroxides [14-16], transition metal sulfides [17], transition metal nitrides/carbides [18, 19], and conductive polymers [20, 21]. Among these, carbon materials, such as reduced graphene oxide or graphene [22, 23], carbon nanotubes [24], porous carbon [25], active carbon [26], and carbon nanofibers [27], are the most potential candidate for supercapacitor electrode materials [28]. Especially, reduced graphene oxides are regarded as the most promising electrode materials because of their excellent electronic conductivity, good chemical stability, and high oxygen content to enhance the electrolyte infiltration, which is favourable to improve the electrochemical performances. For instance, Cui et al. [29] reported that reduced graphene oxide/carbon nanotube showed a maximum specific capacitance of $272 \mathrm{~F} \mathrm{~g}^{-1}$ at $5 \mathrm{mV} \mathrm{s}^{-1}$ and a potential windows of -0.8 to $0 \mathrm{~V}$. Wu et al. [30] investigated the electrochemical performances of ASCs based on $\mathrm{rGO}$ and polyaniline in $1 \mathrm{M} \mathrm{H}_{2} \mathrm{SO}_{4}$ electrolyte, which showed a specific capacitance of $210 \mathrm{~F} \mathrm{~g}^{-1}$ at $0.3 \mathrm{~A} \mathrm{~g}^{-1}$. Li et al. [31] demonstrated $\mathrm{rGO}$ as negative electrode for asymmetric supercapacitor and delivered a

$\triangle$ Zhi-Qiang Hou, houzq@hust.edu.cn|'School of Chemistry and Chemical Engineering, Zhou Kou Normal University, Zhoukou 466001, Henan, People's Republic of China. ${ }^{2}$ College of Science and Technology, Xinyang College, Xinyang 464000, People's Republic of China.

SN Applied Sciences (2019) 1:47| https://doi.org/10.1007/s42452-018-0059-y

Received: 1 August 2018 / Accepted: 14 November 2018 / Published online: 16 November 2018 
specific capacitance of $182 \mathrm{~F} \mathrm{~g}^{-1}$ at $1 \mathrm{~A} \mathrm{~g}^{-1}$ in $1 \mathrm{M} \mathrm{KOH}$ electrolyte.

Generally, the supercapacitors usually be designed by three strategies of building an aqueous, organic electrolyte or ionic liquid, and all-solid-state supercapacitor. Building a organic/ionic liquid symmetric supercapacitor based on $\mathrm{rGO}$ as electrode material is an effective approach for advanced supercapacitors owe to the wide operation windows and the excellent chemical stability of $\mathrm{rGO}$, resulting in a considerable benefit for practical application in $\mathrm{SC}$. Furthermore, $\mathrm{Et}_{4} \mathrm{NBF}_{4} / \mathrm{AN}$ is considered one of the desirable electrolyte because of its low resistance [32]. Hence, it is worthwhile to fabricate a supercapacitor based on $\mathrm{rGO}$ electrode material in $\mathrm{Et}_{4} \mathrm{NBF}_{4} / \mathrm{AN}$ electrolyte. Herein, we report a simple strategy to prepare $\mathrm{GO} /$ CNTs film electrodes by vacuum filter method and thermal reduced at $300^{\circ} \mathrm{C}$ to obtain a freestanding rGO/CNTs hybrid film as electrode materials. In rGO/CNTs films, rGO nanosheets could provide more active sites accessible to charge storage, resulting in high specific capacitance. Moreover, rGO nanosheets intertwined with carbon nanotubes also enhance mechanical stability, increase active surface area and electrode/electrolyte contact area, provide short diffusion length for ions and electrons and high conductivity to improve electrochemical performance [33-38]. Firstly, the electrochemical behaviors of rGO/ CNTs film electrode is investigated in $1 \mathrm{M} \mathrm{KOH}$ electrolyte using a three-electrode systems. The electrochemical results indicate that the the highest specific capacitance of $221 \mathrm{~F} \mathrm{~g}^{-1}$ is obtained at $1 \mathrm{~A} \mathrm{~g}^{-1}$, along with long cycles life of $102.9 \%$ capacitance retention after 5000 cycles. Moreover, the electrochemical behaviors of $\mathrm{rGO} / \mathrm{CNTs}$ with $1 \mathrm{M}$ $\mathrm{Et}_{4} \mathrm{NBF}_{4} / \mathrm{AN}$ electrolyte are also evaluated in three and two electrode systems. In three electrode systems, rGO/CNTs hybrid film shows a high specific capacitance of $174 \mathrm{~F} \mathrm{~g}^{-1}$ at $1 \mathrm{~A} \mathrm{~g} \mathrm{~g}^{-1}$ and excellent cycle stability. In two electrode systems, a symmetric supercapacitor of $\mathrm{rGO} / \mathrm{CNTs} / / \mathrm{rGO} /$ CNTs exhibits a specific capacitance of $24 \mathrm{~F} \mathrm{~g}^{-1}$ at $1 \mathrm{~A} \mathrm{~g}^{-1}$, an energy density of $20.8 \mathrm{Wh} \mathrm{kg}^{-1}$ at $1.27 \mathrm{Wh} \mathrm{kg}^{-1}$, and excellent cycle life of $86.1 \%$ retention after 5000 cycles. It indicates that the good electrochemical performances of this symmetric supercapacitor has the great potential application value.

\section{Experimental}

\subsection{Preparation of rGO/CNTs hybrid film}

The freestanding hybrid films were built using a simple vacuum filtration and thermal reduced method. Firstly, the mixture of GO disperse and CNTs disperse with a mass of 9:1, were sonicated for $10 \mathrm{~min}$. And GO/CNTs films was obtained by vacuum filtration method [39]. Then the GO/ CNTs film was naturally peeled from the filter film. Finally, a freestanding $\mathrm{rGO} / \mathrm{CNTs}$ hybrid film was obtained at $300^{\circ} \mathrm{C}$ for 30 min under $\mathrm{N}_{2}$ atmosphere.

\subsection{Characterization}

X-ray diffraction (XRD), Field-emission scanning electron microscopy (SEM), and transmission electron microscopy (TEM) were used to certify the structure, morphology, and the composites of as-prepared rGO/CNTs hybrid film.

\subsection{Electrochemical measurements}

The as-prepared $\mathrm{rGO} / \mathrm{CNTs}$ hybrid film $\left(0.785 \mathrm{mg} \mathrm{cm}^{-2}\right)$ was directly pressured between two pieces of nickel foam at $10 \mathrm{kPa}$ pressure to obtain a working electrode. The electrochemical behaviors of working electrode was tested using $1 \mathrm{M} \mathrm{KOH}$ electrolyte, $\mathrm{Hg} / \mathrm{HgO}$ reference electrode, and Pt flake electrode in three-electrode systems. Moreover, the electrochemical behaviors of $\mathrm{rGO} / \mathrm{CNTs}$ hybrid film electrode was evaluated using $\mathrm{Ag} / \mathrm{AgCl}$ reference electrode, Pt flake electrode, and $1 \mathrm{M} \mathrm{Et}_{4} \mathrm{NBF}_{4} / \mathrm{AN}$ electrolyte in three-electrode systems. And a symmetrical supercapacitor based on $\mathrm{rGO} / \mathrm{CNTs}$ film//Ni foam was also tested in $1 \mathrm{M} \mathrm{Et}_{4} \mathrm{NBF}_{4} / \mathrm{AN}$ electrolyte. All the electrochemical tests were conducted using a $\mathrm{CHI} 660 \mathrm{E}$. The specific capacitance $C_{m}\left(\mathrm{~F} \mathrm{~g}^{-1}\right)$, energy density $E_{m}\left(\mathrm{Wh} \mathrm{kg}^{-1}\right)$, and power density $P_{m}\left(\mathrm{~W} \mathrm{~kg}^{-1}\right)$ were determined based on the following equations [40]:

$C_{m}=I \Delta t / m \Delta V$

$E_{m}=C \Delta V^{2} / 2 \times 3.6$

$P_{m}=3600 E_{m} / t$

Herein, $m(\mathrm{~g}), I(\mathrm{~A}), \Delta t(\mathrm{~s}), \Delta U(\mathrm{~V})$ mean the mass of active materials, the charging/discharging current, the discharging time, and the operating voltage, respectively.

\section{Results and discussion}

In this work, $\mathrm{rGO} / \mathrm{CNTs}$ film is prepared at a temperature of $300{ }^{\circ} \mathrm{C}$ under $\mathrm{N}_{2}$ atmosphere, because it can balance specific capacitance and rate capability at this temperature [41]. To better understand the structure, morphology, composite information of $\mathrm{rGO} / \mathrm{CNTs}$ film, it is characterized using XRD, SEM, TEM, Raman, and XPS, respectively. Furthermore, we also evaluate its electrochemical behaviors in $\mathrm{KOH}$ aqueous solution and $\mathrm{Et}_{4} \mathrm{NBF}_{4} / \mathrm{AN}$ electrolyte, respectively. 
XRD patterns peaks of the $\mathrm{rGO} / \mathrm{CNTs}$ film is exhibited in Fig. 1a. And it is observed that only one characterization peak appears at $2 \theta$ value of $25^{\circ}$, which attributes to the carbon peak of rGO/CNTs film (JCPDS Card No. 41-1487). This broad characteristic peak indicates the poor crystalline quality. To better understand the surface information of $\mathrm{rGO} / \mathrm{CNTs}$, XPS analysis is carried out to acknowledge the weight ratio of $\mathrm{C} / \mathrm{O}$ and the chemical bonding of the sample, as given in Fig. 1b-d. From Fig. 1b, the peaks of $\mathrm{C} 1 \mathrm{~s}$ and $\mathrm{O} 1 \mathrm{~s}$ could be apparently observed, and the weight of $O$ element and C element are $19.4 \%$ and $80.6 \%$ in $\mathrm{rGO} / \mathrm{CNTs}$ samples, respectively. The $\mathrm{C}$ spectra of $\mathrm{rGO} /$ CNTs samples is presented in Fig. 1c. Four main peaks at
$284.6 \mathrm{eV}, 286.4,288.1$, and $289.9 \mathrm{eV}$ are assigned to the groups of $\mathrm{C}=\mathrm{C}, \mathrm{C}-\mathrm{O}-\mathrm{C}, \mathrm{C}=\mathrm{O}$, and $\mathrm{C}(\mathrm{O}) \mathrm{OH}$, respectively [42]. Figure $1 d$ shows the $O$ spectra of $r G O / C N T s$ films. It is observed that the groups of $\mathrm{C}=\mathrm{O}, \mathrm{C}-\mathrm{O}-\mathrm{C}$, and $\mathrm{C}(\mathrm{O}) \mathrm{OH}$ are locked at peaks of 531.7,533, and $535.1 \mathrm{eV}$, respectively [42]. This reveals that $\mathrm{rGO} / \mathrm{CNTs}$ samples mainly contain $\mathrm{C}=\mathrm{C}, \mathrm{C}-\mathrm{O}-\mathrm{C}, \mathrm{C}=\mathrm{O}$, and $\mathrm{C}(\mathrm{O}) \mathrm{OH}$ groups, which can favor the electrolyte infiltration to improve the specific capacitance. Additionally, the as-prepared $\mathrm{rGO} / \mathrm{CNTs}$ film is also characterized by Raman spectroscopy, because Raman spectrum analysis is regarded as one of most effective strategy to identify carbon-based materials. As shown in Fig. 1e, it demonstrates that Raman peaks at 1346 and $1586 \mathrm{~cm}^{-1}$
Fig. 1 a XRD patterns of rGO/CNTs (JCPDS Card No. 41-1487); b XPS survey spectra for $\mathrm{rGO} / \mathrm{CNTs}$; XPS spectra for $\mathrm{C} 1 s$ (c) and $\mathrm{O} 1 \mathrm{~s}$ (d); e Raman spectra of $\mathrm{rGO} / \mathrm{CNTS}$
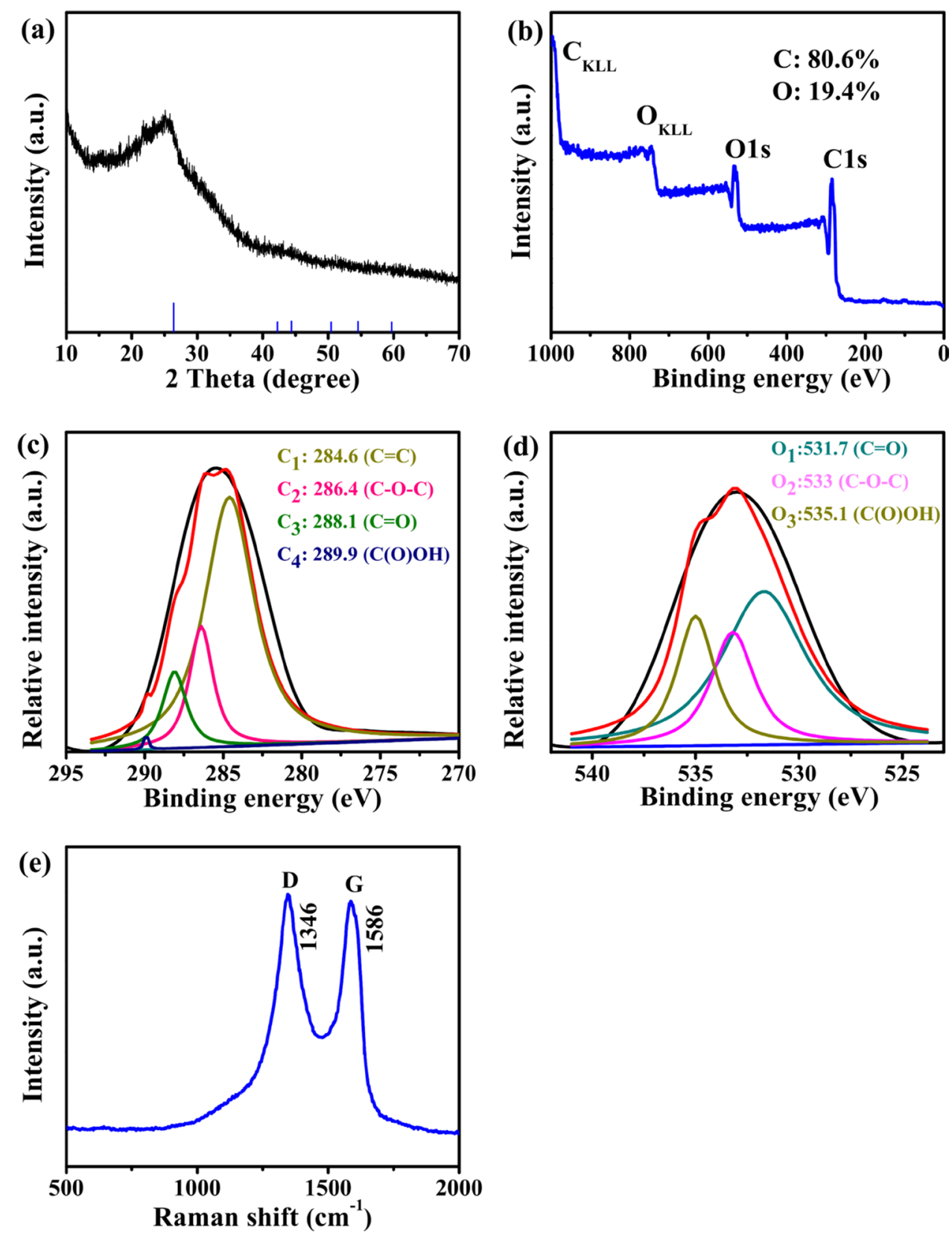
attribute to D-band and G-band of rGO/CNTs film. And 1.03 of $\mathrm{I}_{\mathrm{D}} / \mathrm{I}_{\mathrm{G}}$ means that $\mathrm{rGO} / \mathrm{CNTs}$ samples can provide the good electrical conductivity due to GO samples removal the functional groups of carboxyl, hydroxyl, and epoxy at $300^{\circ} \mathrm{C}[41]$.

To acknowledge the detailed morphology, the as-prepared $\mathrm{rGO} / \mathrm{CNTs}$ films are characterized using SEM and TEM, and the morphology information of these films is exhibited in Fig. 2. From Fig. 2a, it is easily founded that the surface of $\mathrm{rGO} / \mathrm{CNTs}$ films shows $\mathrm{rGO}$ junction with carbon nanotubes, which reveals that $\mathrm{rGO} / \mathrm{CNTs}$ films could provide good mechanical stability and more active sites for ions. The EDS mapping of $C$ and $O$ elements further exhibits the consists of rGO/CNTs films (Fig. 2b, c). After rGO/ CNTs films sonicated in ethanol solvent for several minutes, the rGO/CNTs films are further examined by the TEM images in Fig. 2d-f. As shown in Fig. $2 d$, it is observed that the $\mathrm{rGO}$ nanosheets intertwine with carbon nanotubes and the diameter of carbon nanotubes is round $20 \mathrm{~nm}$. In Fig. 2e, it is easily observed that the carbon nanotube junction with the reduced graphene oxide lead to the good mechanical strength and flexibility. We can clearly observe the interface of carbon nanotube junction with reduced graphene oxide in Fig. $2 f$.

Firstly, cyclic voltammetry (CV), galvanostatic charge-discharge (GCD), and cycle stability are conducted in $1 \mathrm{M} \mathrm{KOH}$ electrolyte via a three-electrode system to explore electrochemical properties of $\mathrm{rGO} / \mathrm{CNTs}$ electrode. $\mathrm{CV}$ tests for $\mathrm{rGO} / \mathrm{CNTs}$ electrode are performed at different scan rates of $25-500 \mathrm{mV} \mathrm{s}^{-1}$ and a potential window of -0.8 to $0 \mathrm{~V}$ (Fig. 3a). These CV curves show a rectangular shape at $25,50,100$, and $200 \mathrm{mV} \mathrm{s}^{-1}$, respectively.
And even at a high scan rate of $500 \mathrm{mV} \mathrm{s}^{-1}$, the shape of curve still keep a similar to that at $25 \mathrm{mV} \mathrm{s}^{-1}$, suggesting the good rate capability of $\mathrm{rGO} / \mathrm{CNTS}$ electrode. Figure $3 \mathrm{~b}$ shows the GCD curves at current densities of 1, 2, 3, 4, and $5 \mathrm{~A} \mathrm{~g} \mathrm{~g}^{-1}$, respectively. All the GCD curves are close to symmetric triangle, suggesting an excellent reversible reaction. The specific capacitances of $\mathrm{rGO} / \mathrm{CNTS}$ electrode are $221,194,182,174$ and $170 \mathrm{~F} \mathrm{~g}^{-1}$ at 1, 2, 3, 4, and $5 \mathrm{~A} \mathrm{~g}^{-1}$, respectively. Meanwhile, the capacitance of $\mathrm{rGO} /$ CNTs electrode can keeps $71 \%$ when the current densities increase from 1 to $10 \mathrm{~A} \mathrm{~g}^{-1}$, indicating a good rate capability (Fig. $3 c$ ). Figure $3 d$ reveals the capacitances gradually increase with the increasing cycle numbers for $\mathrm{rGO} / \mathrm{CNTs}$ electrode, the capacitance retention of $102.9 \%$ could be kept after 5000 cycles at $100 \mathrm{mV} \mathrm{s}^{-1}$, indicating the excellent cycle stability. This electrochemical results indicate that $\mathrm{rGO} / \mathrm{CNT}$ s film could be regarded as an ideal supercapacitors electrode material. Figure $3 e$ gives the electrochemical impedance spectroscopy (EIS) plots of $\mathrm{rGO} / \mathrm{CNTs}$ films and an equivalent circuit, indicating the low resistance of $\mathrm{rGO} / \mathrm{CNTS}$ films.

The electrochemical properties of $\mathrm{rGO} / \mathrm{CNTs}$ are also investigated through three-electrode measured systems in $1 \mathrm{M} \mathrm{Et}_{4} \mathrm{NBF}_{4} / \mathrm{AN}$ electrolyte, as depicted in Fig. 4. The suitable potential windows for $\mathrm{rGO} / \mathrm{CNTs}$ electrode are chosen among -1 to $0,-1$ to $0.5,-1$ to 1 , and -1 to $1.5 \mathrm{~V}$. It reveals that -1 to $1.5 \mathrm{~V}$ could be chosen as the suitable potential window (Fig. 4a). So all the following of electrochemical tests are performed at the suitable windows of -1 to $1.5 \mathrm{~V}$. Figure $4 \mathrm{~b}$ depicts the CV curves at current densities of $10-50 \mathrm{mV} \mathrm{s}^{-1}$. These $\mathrm{CV}$ curves show a similar rectangular shape, suggesting a good capacitive
Fig. 2 a SEM images of $\mathrm{rGO} /$ CNTs samples; b, c EDS mapping of $\mathrm{C}$ and $\mathrm{O}$ element, respectively; d, e TEM images of $\mathrm{rGO} / \mathrm{CNTS}$ samples; $\boldsymbol{f}$ the magnified TEM images in (e)
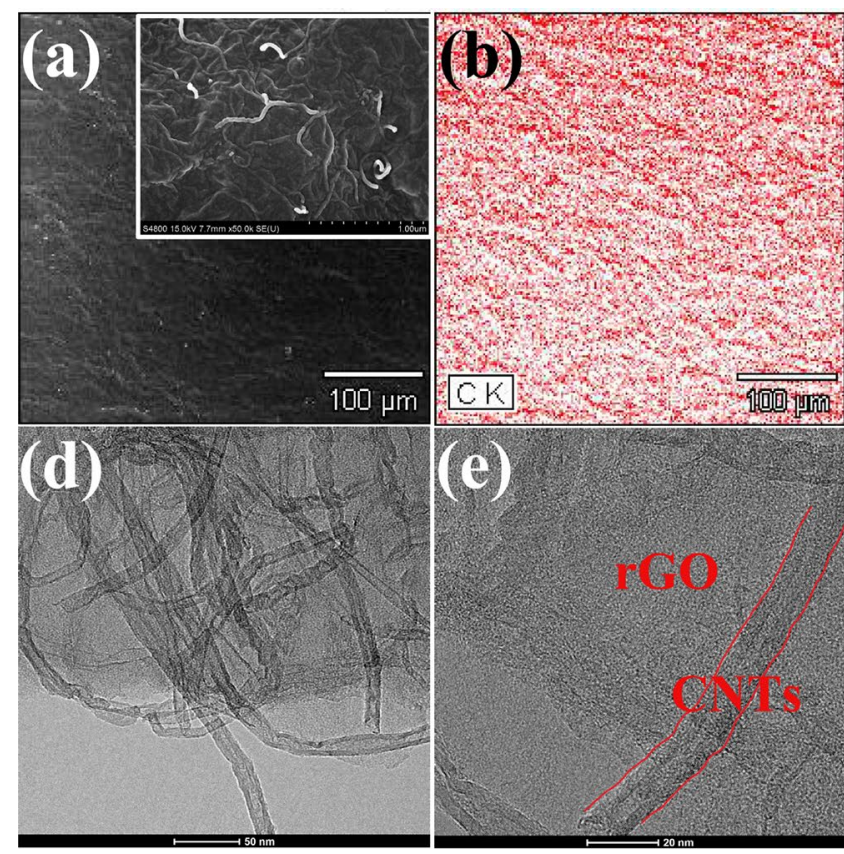
Fig. 3 Electrochemical behaviors of $\mathrm{rGO} / \mathrm{CNTS}$ electrodes based on the three-electrode systems in $1 \mathrm{M} \mathrm{KOH}$ electrode. a CV curves at various scan rates; $\mathbf{b}$ GCD curves at various current densities; c specific capacitance versus current density; $\mathbf{d}$ cycle stability; e EIS plots of $\mathrm{rGO} / \mathrm{CNTs}$ film in $1 \mathrm{M}$ $\mathrm{KOH}$ electrolyte, the inset is equivalent circuit
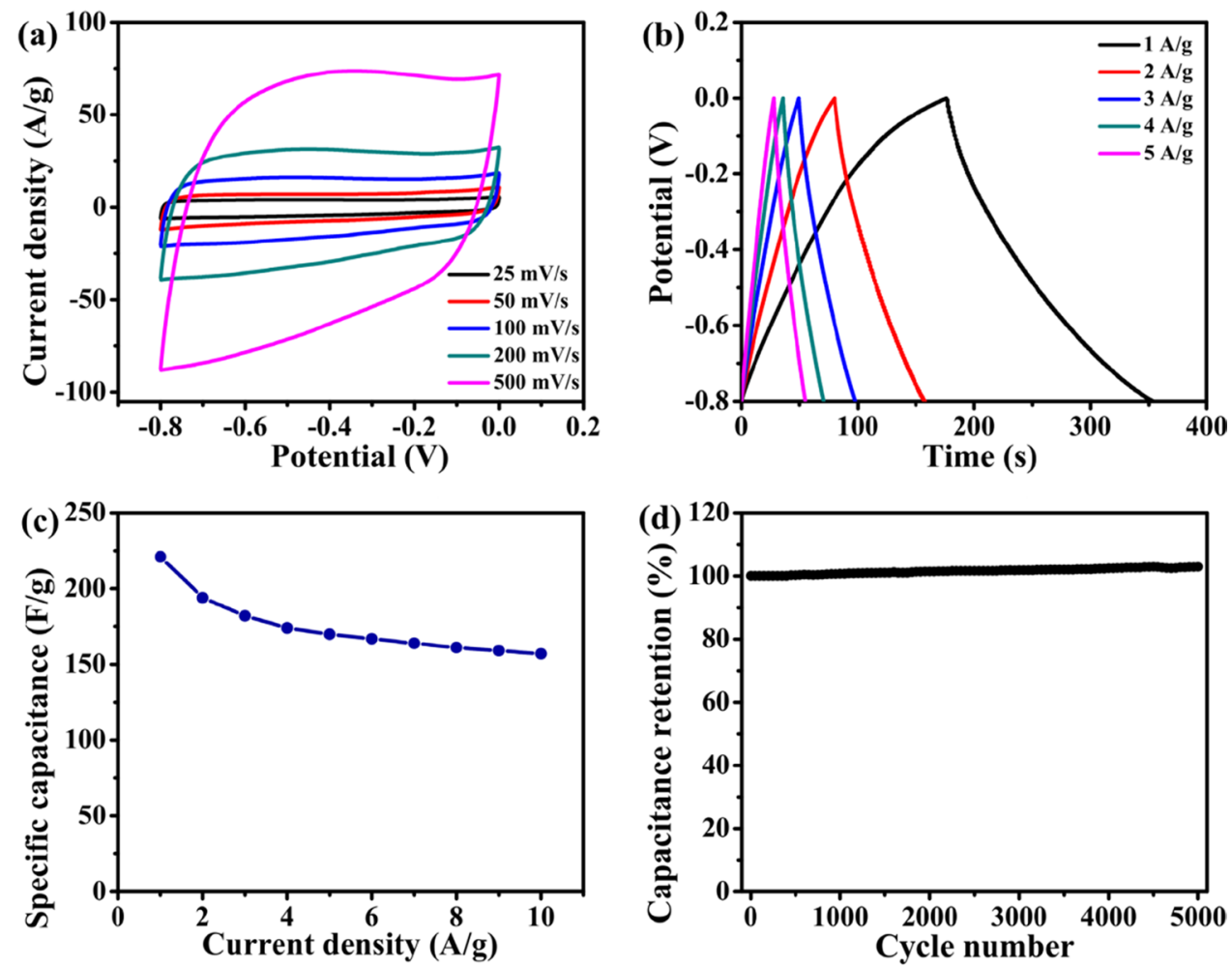

property. Figure $4 c$ depicts the GCD curves measured for $\mathrm{rGO} / \mathrm{CNTs}$ electrode between 2 and $10 \mathrm{~A} \mathrm{~g}^{-1}$. The shape of GCD curves show a symmetrical triangular with slight curvature at 2-10 $\mathrm{A} \mathrm{g}^{-1}$, revealing a good capacitive property. The rate capability for $\mathrm{rGO} / \mathrm{CNTs}$ electrode at 2-10 $\mathrm{A} \mathrm{g}^{-1}$ is shown in Fig. $4 \mathrm{~d}$. The highest specific capacitance of $174 \mathrm{~F} \mathrm{~g}^{-1}$ is obtained at $2 \mathrm{~A} \mathrm{~g}^{-1}$. These values begin a obvious decrease from 3 to $20 \mathrm{~A} \mathrm{~g}^{-1}$. And the capacity retention could reach to $73.6 \%$ for $\mathrm{rGO} / \mathrm{CNTs}$ electrode when the current densities vary from 2 to $20 \mathrm{~A} \mathrm{~g}^{-1}$. It reveals that the $\mathrm{rGO} / \mathrm{CNTs}$ electrode has the good electrochemical behaviors in $\mathrm{Et}_{4} \mathrm{NBF}_{4} / \mathrm{AN}$ electrolyte. Similarly, Fig. 4e also shows the electrochemical impedance spectroscopy (EIS) plots of $\mathrm{rGO} / \mathrm{CNTs}$ films in $1 \mathrm{M} \mathrm{Et}_{4} \mathrm{NBF}_{4} / \mathrm{AN}$ electrolyte and an equivalent circuit. It also indicate the low resistance of $\mathrm{rGO} / \mathrm{CNTS}$ films in $1 \mathrm{M} \mathrm{Et}_{4} \mathrm{NBF}_{4} / \mathrm{AN}$ electrolyte.
Additionally, we assemble a symmetric SC ( $\mathrm{rGO} /$ CNTs//rGO/CNTs) using two pieces of $\mathrm{rGO} / \mathrm{CNTs}$ films, nickel foams collector, and $1 \mathrm{M} \mathrm{Et}_{4} \mathrm{NBF}_{4} / \mathrm{AN}$ electrolyte. The optimal potential windows is $2.5 \mathrm{~V}$ based on CV tests at various potential windows in two-electrode systems. And the total loading mass of $\mathrm{rGO} / \mathrm{CNTs}$ films is $1.2 \mathrm{mg}$. As Fig. 5a shown, CV curves of the symmetric SC are tested at various scan rates. We observe that the shape of CV curves are irregular rectangular between 10 and $50 \mathrm{mV} \mathrm{s}^{-1}$, and the area of CV curves gradually increase with the increasing scan rates. Figure $5 \mathrm{~b}$ exhibits the GCD curves of the symmetric SC, the specific capacitances of $24,22,20,19.2$, and $19 \mathrm{~F} \mathrm{~g}^{-1}$ are obtained at current densities of $1,2,4,6,8 \mathrm{~A} \mathrm{~g}^{-1}$, respectively. The specific capacitance of symmetric SC can remain $79 \%$ from 1 to $8 \mathrm{~A} \mathrm{~g}^{-1}$ (Fig. $5 \mathrm{C}$ ), revealing an excellent rate 
Fig. 4 Electrochemical behaviors of $\mathrm{rGO} / \mathrm{CNTS}$ electrodes based on the three-electrode systems in $1 \mathrm{M} \mathrm{Et}_{4} \mathrm{NBF}_{4} / \mathrm{AN}$ electrolyte. a CV curves at various potential windows at $10 \mathrm{mV} \mathrm{s}^{-1} ; \mathbf{b}$ CV curves at various scan rates; $c$ GCD curves at various current densities; d specific capacitance versus current density; e EIS plots of $\mathrm{rGO} / \mathrm{CNTs}$ film in $1 \mathrm{M} \mathrm{Et}_{4} \mathrm{NBF}_{4} /$ AN electrolyte, the inset is equivalent circuit
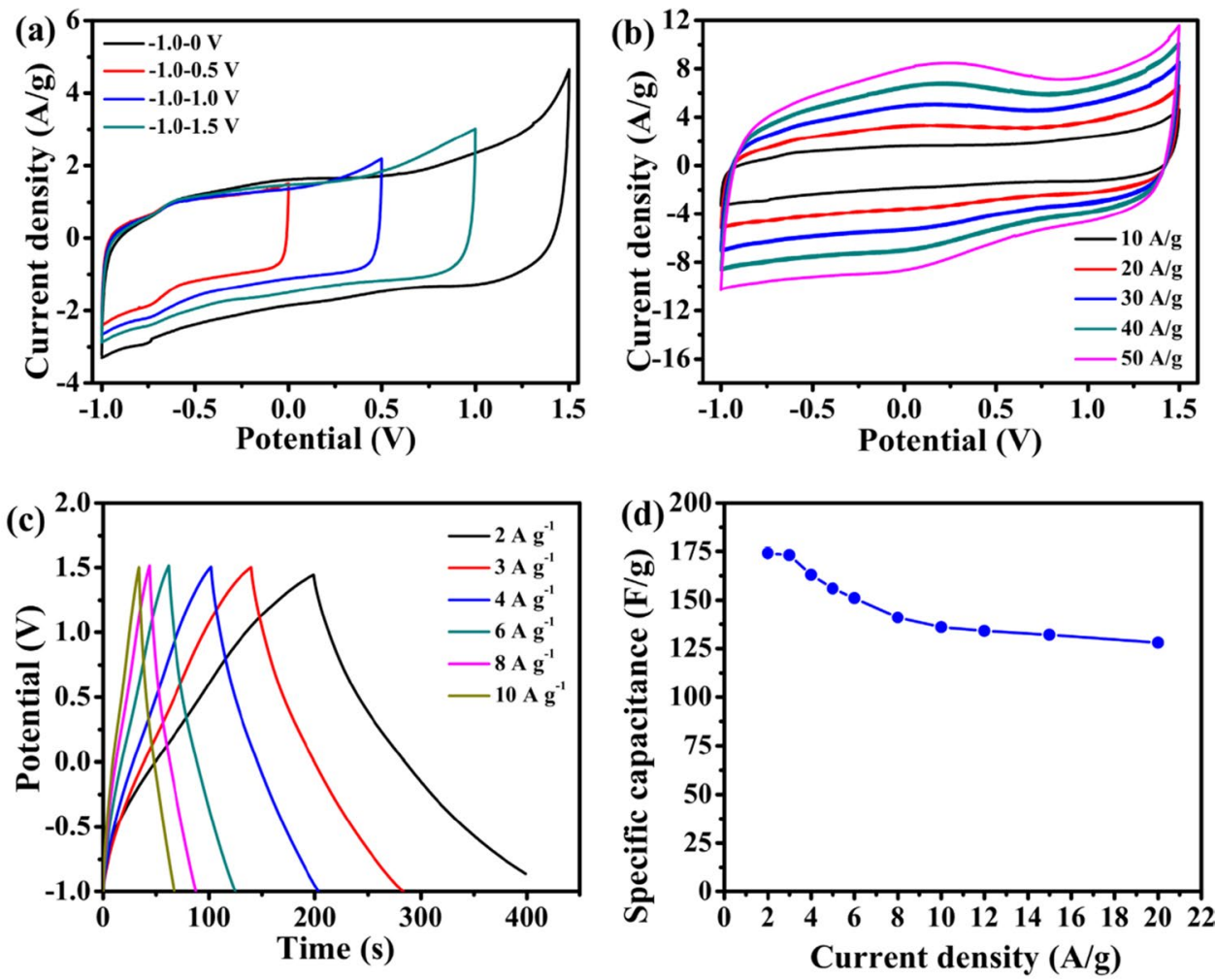

capability. The EIS plots of the symmetric SC is shown in Fig. $5 \mathrm{~d}$. This symmetric SC has the relative low intrinsic resistance due to its low charge-transfer resistance. Figure 5e depicts the Ragone plots of the symmetric SC. The highest energy density of $20.8 \mathrm{Wh} \mathrm{kg}^{-1}$ is obtained at a high power density of $1.27 \mathrm{~kW} \mathrm{~kg}^{-1}$, and still remains $16.5 \mathrm{Wh} \mathrm{kg}^{-1}$ at $9.85 \mathrm{~kW} \mathrm{~kg}^{-1}$. The energy density of this symmetric SC is higher than that of the previous reported, such as $5.7 \mathrm{Wh} \mathrm{kg}^{-1}$ of APCN-2 at $10 \mathrm{~kW} \mathrm{~kg}^{-1}$ [43], $13.4 \mathrm{Wh} \mathrm{kg}^{-1}$ of $\mathrm{Ni}(\mathrm{OH})_{2} /$ UGF//a-MEGO at $0.065 \mathrm{~kW} \mathrm{~kg}^{-1}$ [44], $13.55 \mathrm{Wh} \mathrm{kg}^{-1}$ of N-RC2//N-RC2 symmetric supercapacitor at $0.3998 \mathrm{~kW} \mathrm{~kg}^{-1}$ [45], $20.3 \mathrm{Wh} \mathrm{kg}^{-1}$ of $\mathrm{AC} / / \mathrm{Ni}(\mathrm{OH})_{2}$ ASC at $0.0906 \mathrm{~kW} \mathrm{~kg}^{-1}$ [46]. In Fig. 5f, the symmetric SC shows a good cycle stability of $86.1 \%$ capacitance retention after 5000 cycles.

\section{Conclusions}

In this work, we fabricate the freestanding $\mathrm{rGO} / \mathrm{CNTs}$ hybrid films via the simple methods of vacuum filtration and thermal reduction. The electrochemical performances of $\mathrm{rGO} / \mathrm{CNTs}$ film in three-electrode systems exhibit a maximum specific capacitance of $221 \mathrm{~F} \mathrm{~g}^{-1}$, a $71 \%$ capacitance retention, and an excellent cycle life in $1 \mathrm{M} \mathrm{KOH}$ electrolyte. We also investigate the electrochemical performances of $\mathrm{rGO} / \mathrm{CNTs}$ films in $\mathrm{Et}_{4} \mathrm{NBF}_{4} /$ AN electrolyte under three-electrode systems. The results demonstrate a maximum specific capacitance of $174 \mathrm{~F} \mathrm{~g}^{-1}$ and good rate capability. Moreover, a symmetric supercapacitor of $\mathrm{rGO} / \mathrm{CNTs} / / \mathrm{rGO} / \mathrm{CNTs}$ demonstrates 
Fig. 5 Electrochemical behaviors of $\mathrm{rGO} / \mathrm{CNTs} / / \mathrm{rGO} / \mathrm{CNTs}$ symmetric $\mathrm{SC}$ in $1 \mathrm{M} \mathrm{Et}_{4} \mathrm{NBF}_{4} /$ AN electrolyte. a CV curves of symmetric SC at various scan rates; $\mathbf{b}$ GCD curves of symmetric SC at various current densities; c specific capacitance versus current density; d EIS plots of symmetric SC; $\mathbf{e}$ Ragone plots; f cycle performances
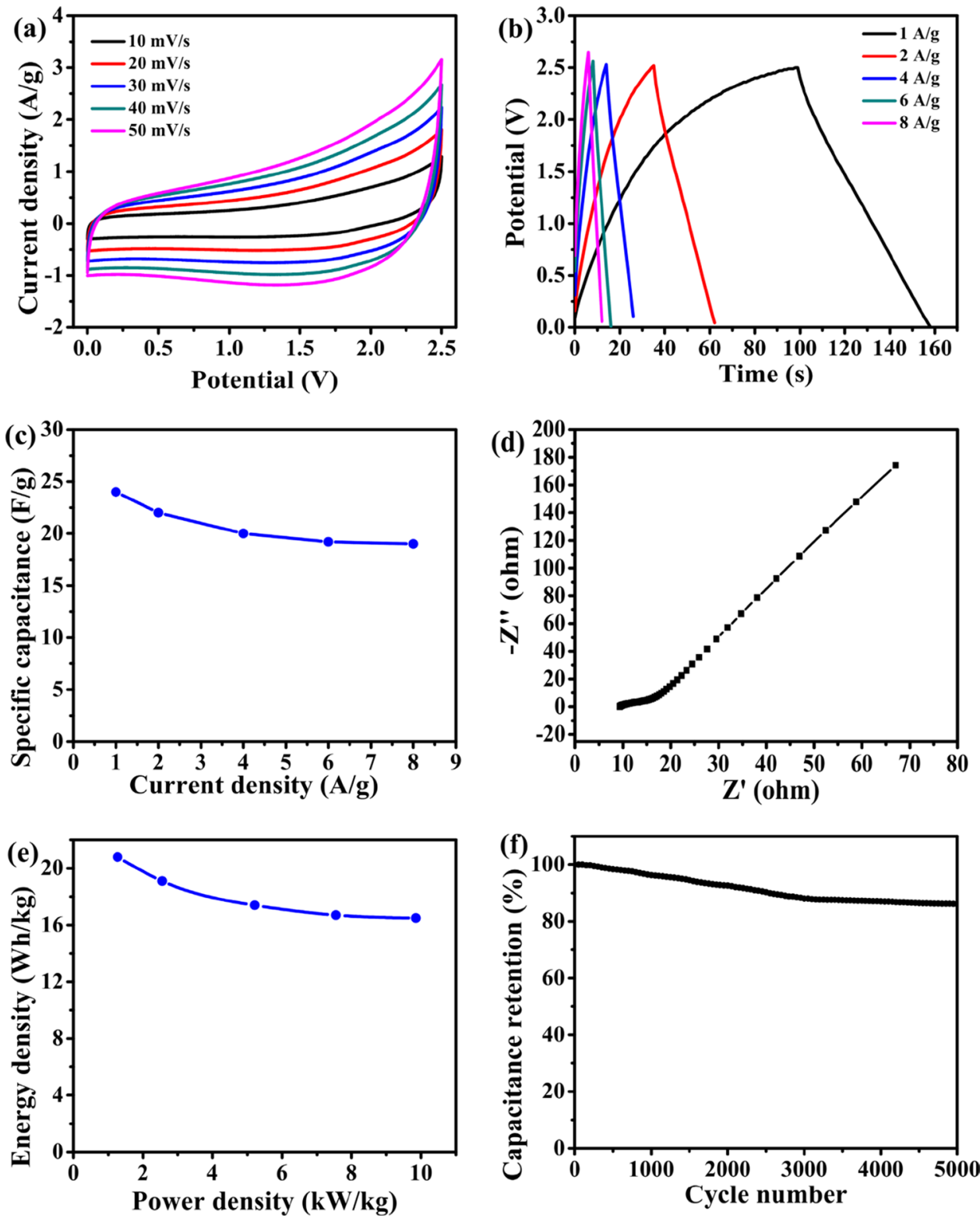

a maximum specific capacitance of $24 \mathrm{~F} \mathrm{~g}^{-1}$ at $2 \mathrm{~A} \mathrm{~g}^{-1}$, a energy density of $20.8 \mathrm{Wh} \mathrm{kg}^{-1}$ at $1.27 \mathrm{~kW} \mathrm{~kg}^{-1}$ and an excellent cycle life of $86.1 \%$ retention after 5000 cycles. It suggests that the symmetric SC has a great potential in practical application.

Acknowledgements This work was supported by the School-based Program of Zhoukou Normal University (ZKNUB 1201804), Programs for Science and Technology Development of Henan Province (172102310626), Key Scientific Research Project of Henan Province (18B150024), Key Project of Xinyang College (2017zd03), Xinyang College Students' Innovative Entrepreneurial Training Program (CX20171002), High Level Personal Fund of Zhou Kou Normal University (ZKNUC2017043), Key Research Project of Henan Higher Education Institute (19A150052).

\section{Compliance with ethical standards}

Conflict of interest The authors declare that they have no conflict of interest.

\section{References}

1. Xiong $T$, Tan TL, Lu L, Lee WSV, Xue JM (2018) Harmonizing energy and power density toward $2.7 \mathrm{~V}$ asymmetric aqueous supercapacitor. Adv Energy Mater 8:1702630. https://doi. org/10.1002/aenm.201702630

2. Zhao Jian, Li Zhenjiang, Yuan Xiangcheng, Yang Zhen, Zhang Meng, Meng Alan, Li Qingdang (2018) A high-energy density asymmetric supercapacitor based on $\mathrm{Fe}_{2} \mathrm{O}_{3}$ nanoneedle arrays 
and $\mathrm{NiCO}_{2} \mathrm{O}_{4} / \mathrm{Ni}(\mathrm{OH})_{2}$ hybrid nanosheet arrays grown on $\mathrm{SiC}$ nanowire networks as free-standing advanced electrodes. Adv Energy Mater 8:1702787. https://doi.org/10.1002/aenm.20170 2787

3. Thangavel R, Kannan AG, Ponraj R, Thangavel V, Kim DW, Lee YS (2018) High-energy green supercapacitor driven by ionic liquid electrolytes as an ultra-high stable next-generation energy storage device. J Power Sources 383:102-109. https:// doi.org/10.1016/j.jpowsour.2018.02.037

4. Su LJ, Lei SL, Liu L, Liu LY, Zhang YF, Shi SQ, Yan XB (2018) Sprinkling $\mathrm{MnFe}_{2} \mathrm{O}_{4}$ quantum dots on nitrogen-doped graphene sheets: the formation mechanism and application for high-performance supercapacitor electrodes. J Mater Chem A 6:997-10007. https://doi.org/10.1039/C8TA02982B

5. Li J, Hao C, Zhou SS, Huang CX, Wang XH (2018) Synthesis and characterization of polypyrrole/nickel hydroxide/sulfonated graphene oxide ternary composite for all-solid-state asymmetric supercapacitor. Electrochim Acta 283:467-477. https://doi. org/10.1016/j.electacta.2018.06.155

6. Cho S, Patil B, Yu S, Ahn S, Hwang J, Park C, Do K, Ahn H (2018) Flexible, Swiss roll, fiber-shaped, asymmetric supercapacitor using $\mathrm{MnO}_{2}$ and $\mathrm{Fe}_{2} \mathrm{O}_{3}$ on carbon fibers. Electrochim Acta 269:499-508. https://doi.org/10.1016/j.electacta.2018.03.020

7. Wu FS, Wang XH, Zheng WR, Gao HW, Hao C, Ge CW (2017) Synthesis and characterization of hierarchical $\mathrm{Bi}_{2} \mathrm{MoO}_{6} /$ polyaniline nanocomposite for all-solid-state asymmetric supercapacitor. Electrochim Acta 245:685-695. https://doi.org/10.1016/j.elect acta.2017.05.165

8. Yang SH, Han ZZ, Zheng FY, Sun J, Qiao ZS, Yang XP, Li L, Li CC, Song XF, Cao BQ (2018) $\mathrm{ZnFe}_{2} \mathrm{O}_{4}$ nanoparticles-cotton derived hierarchical porous active carbon fibers for high rate-capability supercapacitor electrodes. Carbon 134:15-21. https://doi. org/10.1016/j.carbon.2018.03.071

9. Kang JL, Hirata A, Qiu HJ, Chen LY, Ge XB, Fujita T, Chen MW (2014) Self-grown oxy-hydroxide @nanoporous metal electrode for high-performance supercapacitors. Adv Mater 26:269-272. https://doi.org/10.1002/adma.201302975

10. Si WP, Yan CL, Chen Y, Oswald S, Han LY, Schmidt OG (2013) On chip, all-solid-state and flexible micro-supercapacitors with high performance based on $\mathrm{MnO}_{\mathrm{x}} /$ Au multilayers. Energy Environ Sci. 6:3218-3223. https://doi.org/10.1039/C3EE41286E

11. Emiliano MP, Michael PD, Carlos G, Encarnación L, Félix Z, Craig EB (2017) Antimonene: a novel 2D nanomaterial for supercapacitor applications. Adv Energy Mater 8:1702606. https://doi. org/10.1002/aenm.201702606

12. Nam I, Kim GP, Park S, Han JW, Yi J (2014) All-solid-state, origami-type foldable supercapacitor chips with integrated series circuit analogues. Energy Environ Sci 7:1095-1102. https://doi. org/10.1039/C3EE43175D

13. Zhao YF, Ran W, He J, Huang YZ, Liu ZF, Liu W, Tang YF, Zhang L, Gao DW, Gao FM (2015) High-performance asymmetric supercapacitors based on multilayer $\mathrm{MnO}_{2}$ /graphene oxide nanoflakes and hierarchical porous carbon with enhanced cycling stability. Small 11:1310-1319. https://doi.org/10.1002/smll.201401922

14. Gao HW, Hao C, Qi Y, Li J, Wang XH, Zhou SS, Huang CX (2018) In situ hydrothermal construction of hydrogel composites by anchoring $\mathrm{Ni}(\mathrm{OH})_{2}$ nanoparticles onto sulfonated graphene and their application for functional supercapacitor electrode. J Alloys Compd 767:1048-1056. https://doi.org/10.1016/j.jallc om.2018.07.181

15. Zhou SS, Hao C, Wang JJ, Wang XH, Gao HW (2018) Metalorganic framework templated synthesis of porous $\mathrm{NiCO}_{2} \mathrm{O}_{4} /$ $\mathrm{ZnCO} \mathrm{O}_{4} / \mathrm{Co}_{3} \mathrm{O}_{4}$ hollow polyhedral nanocages and their enhanced pseudocapacitive properties. Chem Eng J 351:74-84. https://doi.org/10.1016/j.cej.2018.06.070
16. Hou ZQ, Tian FS, Gao YP, Wu W, Yang LX, Jia XL, Huang KJ (2018) Nickel cobalt hydroxide/reduced graphene oxide/carbon nanotubes for high performance aqueous asymmetric supercapacitors. J Alloys Compd 753:525-531. https://doi.org/10.1016/j.jallc om.2018.04.245

17. Gao YP, Wu X, Huang KJ, Xing LL, Zhang YY, Liu L (2017) Twodimensional transition metal diseleniums for energy storage application: a review of recent developments. CrystEngComm 19:404-418. https://doi.org/10.1039/C6CE02223E

18. Yoon Y, Lee M, Kim SK, Bae G, Song W, Myung S, Lim J, Lee SS, Zyung T, An KS (2018) A strategy for synthesis of carbon nitride induced chemically doped 2D MXene for high-performance supercapacitor electrodes. Adv Energy Mater 8:1703173. https ://doi.org/10.1002/aenm.201703173

19. Cedric C, Mohamed A, Katherine LVA, Narendra K, Luisa G, Adriana MNS, Babak A, Husam NA, Yury G (2018) Asymmetric flexible MXene-reduced graphene oxide micro-supercapacitor. Adv Electron Mater 4:1700339. https://doi.org/10.1002/aelm.20170 0339

20. Zhou K, He Y, Xu QC, Zhang Q, Zhou AA, Lu ZH, Yang LK, Jiang Y, Ge DT, Liu XY, Bai H (2018) A hydrogel of ultrathin pure polyaniline nanofibers: oxidant-templating preparation and supercapacitor application. ACS Nano 12:5888-5894. https://doi. org/10.1021/acsnano.8b02055

21. Chang ZH, Feng DY, Huang ZH, Liu XX (2018) Electrochemical deposition of highly loaded polypyrrole on individual carbon nanotubes in carbon nanotube film for supercapacitor. Chem Eng J 337:552-559. https://doi.org/10.1016/j.cej.2017.12.095

22. Volker S, Kris M, Matthew DK, Maher EK, Richard BK (2018) A simple route to porous graphene from carbon nanodots for supercapacitor applications. Adv Mater 30:1704449. https:// doi.org/10.1002/adma.201704449

23. Xu B, Wang HR, Zhu QZ, Sun N, Anasori B, Hu LF, Wang F, Guan $X B$, Gogotsi $Y$ (2018) Reduced graphene oxide as a multifunctional conductive binder for supercapacitor electrodes. Energy Storage Mater 12:128-136. https://doi.org/10.1016/j. ensm.2017.12.006

24. Patiño J, Salas NL, Gutiérrez MC, Carriazo D, Ferrer ML, Monte F (2018) Correction:phosphorus-doped carbon-carbon nanotube hierarchical monoliths as true three-dimensional electrodes in supercapacitor cells. J Mater Chem A 6:2847-2848. https://doi. org/10.1039/C7TA90286G

25. Qie $L$, Chen $W M, X u H H$, Xiong XQ, Jiang $Y$, Zou F, Hu XL, Xin $Y$, Zhang ZL, Huang YH (2013) Synthesis of functionalized 3D hierarchical porous carbon for high-performance supercapacitors. Energy Environ Sci 6:2497-2504. https://doi.org/10.1039/C3EE4 $1638 \mathrm{~K}$

26. Gao YP, Huang KJ, Wu X, Hou ZQ, Liu YY (2018) MoS 2 nanosheets assembling three-dimensional nanospheres for enhanced-performance supercapacitor. J Alloys Compd 741:174-181. https:// doi.org/10.1016/j.jallcom.2018.01.110

27. Ma C, Ruan SJ, Wang JT, Long DH, Qiao WM, Ling LC (2018) Freestanding carbon nanofiber fabrics for high performance flexible supercapacitor. J Colloid Interface Sci 531:513-522. https://doi. org/10.1016/j.jcis.2018.06.093

28. Wang Q, Yan J, Fan ZJ (2016) Carbon materials for high volumetric performance supercapacitors: design, progress, challenges and opportunities. Energy Environ Sci 9:729-762. https://doi. org/10.1039/c5ee03109e

29. Cui XY, Lv RT, Sagar RUR, Liu C, Zhang ZJ (2015) Reduced graphene oxide/carbon nanotube hybrid film as high performance negative electrode for supercapacitor. Electrochim Acta 169:342-350. https://doi.org/10.1016/j.electacta.2015.04.074

30. Wu Q, Xu YX, Yao ZY, Liu AR, Shi GQ (2010) Supercapacitors based on flexible graphene/polyaniline nanofiber composite 
films. ACS Nano 4:1963-1970. https://doi.org/10.1021/nn100 0035

31. Li Y, Zhao D (2015) Preparation of reduced graphite oxide with high volumetric capacitance in supercapacitors. Chem Commun 51:5598-5601. https://doi.org/10.1039/C4CC08038F

32. Clevenger B, Ruoff RS (2012) Highly conductive and porous activated reduced graphene oxide films for high-power supercapacitors. Nano Lett. 12:1806-1812. https://doi.org/10.1021/ $\mathrm{nl} 203903 z$

33. Cui XY, Lv RT, Sagar RUR, Liu C, Zhang ZJ (2015) Reduced graphene oxide/carbon nanotube hybrid film as high performance negative electrode for supercapacitor. Electrochim Acta 169:342-350. https://doi.org/10.1016/j.electacta.2015.04.074

34. Tourani S, Rashidi AM, Safekordi AA, Aghabozorg HR, Khorasheh $F$ (2015) Synthesis of reduced graphene oxide-carbon nanotubes (rGO-CNT) composite and its use as a novel catalyst support for hydro-purification of cude terephthalic acid. Ind Eng Chem Res 54:7591-7603. https://doi.org/10.1021/acs.iecr.5b015 74

35. Liu D, Du PC, Wei WL, Wang HX, Liu P (2017) Flexible and robust sandwich-structured S-doped reduced graphene oxide/carbon nanotubes/polyaniline (S-rGO/CNTs/PANI) composite membranes: excellent candidate as free-standing electrodes for highperformance supercapacitors. Electrochim Acta 233:201-209. https://doi.org/10.1016/j.electacta.2017.03.040

36. Xiong CY, Li TH, Zhao TK, Dang A, Li H, Ji XL, Jin WB, Jiao SS, Shang YD, Zhang YG (2017) Reduced graphene oxide-carbon nanotube grown on carbon fiber as binder-free electrode for flexible high-performance fiber supercapacitors. Compos Part B 116:7-15. https://doi.org/10.1016/j.compositesb.2017.02.028

37. Youn HC, Bak SM, Park SH, Yoon SB, Roh KC, Kim KB (2014) Onestep preparation of reduced graphene oxide/carbon nanotube hybrid thin film by electrostatic spray deposition for supercapacitor applications. Met Mater Int 20:975-981. https://doi. org/10.1007/s12540-014-5024-8

38. Yang WY, Chen Y, Wang JF, Peng TJ, Xu JH, Yang BC, Tang K (2018) Reduced graphene oxide/carbon nanotube composites as electrochemical energy storage electrode applications. Nanoscale Res Lett 13:181. https://doi.org/10.1186/s11671-018-2582-6
39. Hou ZQ, Wang ZY, Yang LX, Yang ZG (2017) Nitrogen-doped reduced graphene oxide intertwined with $\mathrm{V}_{2} \mathrm{O}_{3}$ nanoflakes as self-supported electrodes for flexible all-solid-state supercapacitors. RSC Adv 7:25732-25739. https://doi.org/10.1039/c7ra0 $2899 \mathrm{~g}$

40. Gao YP, Huang KJ, Zhang CX, Song SS, Wu X (2018) High performance symmetric supercapacitor based on flower-like zinc molybdate. J Alloys Compd 731:1151-1158. https://doi. org/10.1016/j.jallcom.2017.10.161

41. Zhao B, Liu P, Jiang Y, Pan D, Tao HH, Song JS, Fang T, Xu WW (2012) Supercapacitor performances of thermally reduced graphene oxide. J Power Sources 198:423-427. https://doi. org/10.1016/j.jpowsour.2011.09.074

42. Chen C, Xu GB, Wei XL, Yang LW (2016) A macroscopic threedimensional tetrapod-separated graphene-like oxygenated $\mathrm{N}$-doped carbon nanosheet architecture for use in supercapacitors. J Mater Chem A 4:9900-9909. https://doi.org/10.1039/ c6ta04062d

43. Zhou J, Zhu TT, Xing W, Li ZH, Shen HL, Zhuo SP (2015) Activated polyaniline-based carbon nanoparticles for high performance supercapacitors. Electrochim Acta 160:152-159. https://doi. org/10.1016/j.electacta.2015.04.074

44. Ji JY, Zhang LL, Ji HX, Li Y, Zhao X, Bai X, Fan XB, Zhang FB, Ruoff RS (2013) Nanoporius $\mathrm{Ni}(\mathrm{OH})_{2}$ thin films on $3 \mathrm{D}$ ultrathin-graphite foam for asymmetric supercapacitor. ACS Nano 7:6237-6243. https://doi.org/10.1021/nn4021955

45. Sun KJ, Guo DY, Zheng XP, Zhu YR, Zheng YP, Ma MG, Zhao GH, Ma GF (2016) Nitrogen-doped porous carbon derived from rapeseed residues for high-performance supercapacitors. Int J Electrochem Sci 11:4743-4754. https://doi.org/10.20964 /2016.06.22

46. Yang SN, Cheng K, Ye K, Li YJ, Qu J, Yin JL, Wang GL, Cao DX (2015) A novel asymmetric supercapacitor with buds-like $\mathrm{Co}(\mathrm{OH})_{2}$ used as cathode materials and activated carbon as anode materials. J Electroanal Chem 741:93-99. https://doi.org/10.1016/j.jelec hem.2015.01.011 